\title{
Iodine contamination of the serum protein-bound iodine: Incidence and clinical significance
}

\author{
P. R. PANNALL, P. C. MiNNAAR, AND A. T. NESER
}

From the Departments of Chemical Pathology and Biophysics, University of the Orange Free State, and the South African Institute for Medical Research, Bloemfontein

SYNOPSIS Iodine contamination as defined by the combination of a raised (PBI-T $\left.\mathrm{T}_{4} \mathrm{I}\right)$ difference and low ${ }^{131}$ I neck uptake was found in $38(17.5 \%)$ of 217 euthyroid patients. Of these, 17 had PBI levels of greater than $20 \mu \mathrm{g} / \mathrm{dl}$ but in the remainder levels were clinically feasible. In only 21 was there a history of exposure to iodine. Two of 12 hypothyroid patients had PBI levels well within normal limits. False elevation of the PBI is thus shown to be common. It is neither always obvious nor can it be easily avoided. The PBI is not an acceptable alternative to $\mathrm{T}_{4}$ estimation by other methods.

Thyroid disease is probably the commonest endocrine abnormality encountered in clinical practice and enters into the differential diagnosis of a number of conditions, particularly obesity and anxiety states. When considered, it must be confirmed or excluded by appropriate laboratory investigations (Bayliss and Hall, 1973). The simplest method is the estimation of serum thyroxine $\left(\mathrm{T}_{4}\right)$, preferably with an assessment of thyroxine-binding proteins by a resinuptake test. The product of serum thyroxine and resin uptake, the calculated free thyroxine index (FTI), is accepted as the most reliable single indicator of thyroid secretory function (Bayliss and Hall, 1973).

For the calculation of the FTI either the proteinbound iodine (PBI) or the serum $\mathrm{T}_{4}$, usually determined by a method not measuring iodine, may be used. Recent reviews on the subject (Flynn and Hobbs, 1971; Bayliss and Hall, 1973), while warning against falsely elevated PBI values, nevertheless list this test as an alternative to serum $T_{4}$ measurement. The PBI, which is cheaper and more easily automated than the $T_{4}$ estimation, remains a popular test of thyroid function despite the well known risk of spuriously high results due to iodine contamination (Acland, 1971). This may be due to the belief that contamination is easily recognized by the unrealistically high values obtained, or that it can be avoided by excluding patients who have recently ingested iodine in any form or who have undergone diagnostic procedures involving iodine-containing radioopaque media.

\footnotetext{
Received for publication 6 February 1974
}

The present study was undertaken to test the acceptability of the PBI as an alternative to $\mathrm{T}_{4}$ estimation. There were three main aims: (1) to assess the incidence of iodine contamination in patients referred for thyroid function studies; (2) to see whether such interference is easily recognized or could be prevented; (3) to assess, within the limits of the study, the diagnostic implications of such interference with special reference to the detection of hypothyroidism.

\section{Patients and Methods}

Most methods of PBI estimation employ steps to remove or reduce exogenous iodine contamination, with varying success. It was felt therefore that the best index of a falsely high PBI result would be the difference between the thyroxine iodine measured in the PBI and that calculated from thyroxine measured by a competitive protein-binding technique. This difference, representing non-thyroxine iodine, will be referred to as dI. Exogenous iodine may also cause a falsely low ${ }^{131}$ I neck uptake by enlarging the body iodide pool. It seems therefore reasonable to consider that in euthyroid patients the combination of a low neck uptake and a high dI is evidence of iodine contamination. Such a group was sought among patients referred to us for thyroid function studies.

\section{PATIENTS}

All patients referred were carefully questioned about possible iodine intake during the preceding three months, in the form of cough mixtures, throat 
lozenges, 'traveller's diarrhoea' preparations, eg, Enterovioform (Ciba), and iodine itself. Information on all previous radiological examinations and where possible a detailed history of all drugs was obtained. Patients were also asked whether they habitually used municipal water or well water.

Venous blood was drawn with precautions to avoid exogenous iodine contamination. Disposable syringes and needles were used and blood for PBI estimation was put into clean disposable containers.

\section{METHODS}

Serum $T_{4}$ was measured by a competitive proteinbinding technique (Tetrasorb-125, Abbott Laboratories) and the $\mathrm{T}_{3}$-resin uptake with the Triosorb-125 kit (Abbott Laboratories). The PBI was estimated by a standard AutoAnalyzer (Technicon) method after preliminary removal of inorganic iodide with IRA-400 Amberlite; a rapid sampling screening run detected all grossly elevated values.

The ${ }^{131}$ I neck uptake was measured 24 hours after an oral dose of ${ }^{131}$ I obtained from the Radiochemical Centre, Amersham, using a Nuclear Chicago scintillation counter with collimator according to the specifications of the International Atomic Energy Commission.

\section{CALCULATIONS}

Thyroxine iodine $\left(\mathrm{T}_{4} \mathrm{I}\right)$ was calculated as $\mathrm{T}_{4}(\mu \mathrm{g} / \mathrm{dl})$ $\times 0.653$. The FTI was calculated as the product of the serum $\mathrm{T}_{4}$ (or PBI) and $\mathrm{T}_{3}$-resin uptake and is referred to as FTI(T $\left.\mathrm{T}_{4}\right)$ or FTI(PBI) respectively; as one calculation is based on iodine and the other on thyroxine different numerical values are obtained.

The difference (PBI-T $\left.\mathrm{T}_{4} \mathrm{I}\right)$ was calculated for each sample and is referred to as dI.

\section{Results}

Two hundred and eighty-seven patients were seen. Of these 14 were judged hyperthyroid and 12 hypothyroid on the basis of the test results including, where indicated, stimulation or suppression tests. Twenty-four patients were being treated for thyroid disease and in a further 20 patients the final data were incomplete.

Two hundred and seventeen patients with normal FTI $\left(T_{4}\right)$ values remained for evaluation and, unless otherwise indicated, all results refer to this group.

THE INCIDENCE OF IODINE CONTAMINATION The distribution of the $\mathrm{dI}$ is shown in figure 1 . The scatter and mean of the neck uptakes of different groups of $\mathrm{dI}$ are shown in fig 2 and the results summarized in table $I$. The group of two patients with dI of less than $-2 \cdot 0$ is too small for analysis.

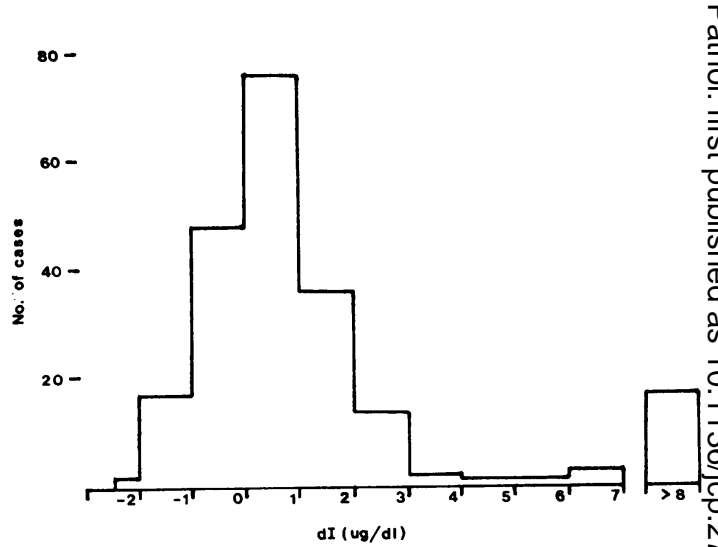

Fig 1 Distribution of dI values

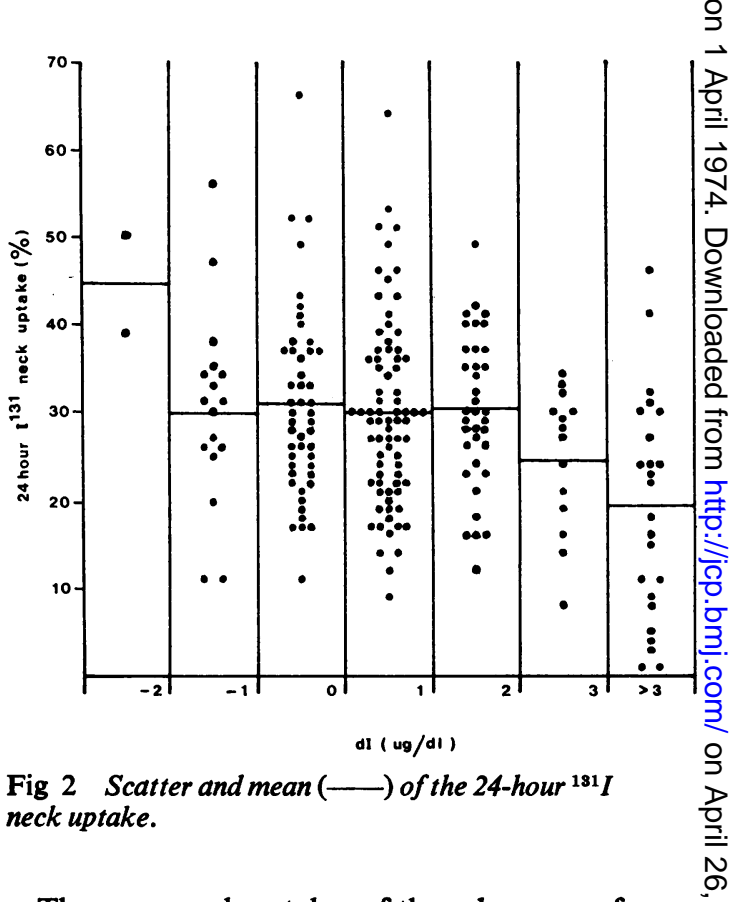

The mean neck uptakes of the subgroups of group A (dI -1.9 to $+2.0 \mu \mathrm{g} / \mathrm{dl})$ did not differ significantly N The mean neck uptakes of the two subgroups of group B, both separately and together, were signix ficantly lower than that of group $A$. The mearf FTI $\left(T_{4}\right)$ did not differ significantly between groups $A$ and $B$ whereas the mean FTI(PBI) was signifi: cantly higher in group $B$. The $\mathbf{T}_{4}$ was within the normal range in all the patients of group $B$, excep $\Phi_{D}$ two who had mildly elevated values of 13.3 and $13 \cdot 4 \mu \mathrm{g} / \mathrm{dl}$ (normal 5.6-12.6).

It was considered therefore that the patients of 


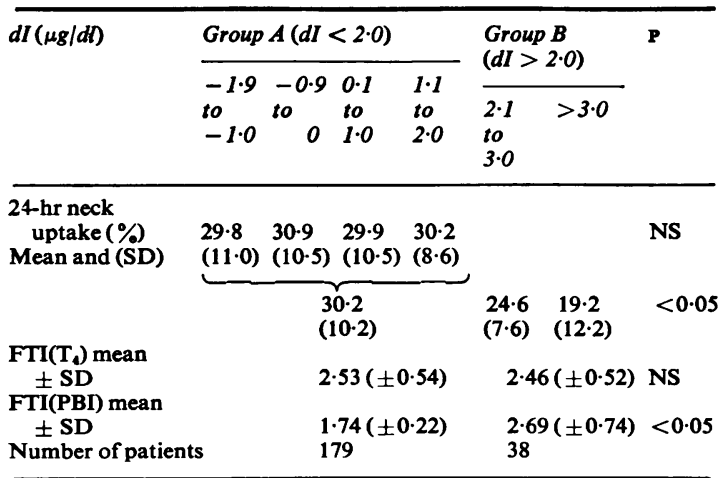

Table I Differences in indices of thyroid function in euthyroid patients with $d I\left(P B I-T_{4} I\right)$ less and greater than $2 \cdot 0 \mu g / d l$

${ }^{1}$ The neck uptakes of both subgroups of B differ significantly from the mean neck uptake of group A. The mean values of FTI(T, $T_{4}$ and FTI(PBI) differ numerically as the former is calculated on thyroxine and the latter on iodine.

group B, ie, those with a dI of greater than $2.0 \mu \mathrm{g} / \mathrm{d}$ showed evidence of iodine contamination. This group contained 38 patients $(17 \cdot 5 \%)$. In 16 the PBI was greater than $20 \mu \mathrm{g} / \mathrm{dl}$ while in the remaining 22 it was less than $16 \mu \mathrm{g} / \mathrm{dl}$. Of these, 13 patients had values of less than $10 \mu \mathrm{g} / \mathrm{dl}$.

\section{SOURCE OF CONTAMINATION}

The history of iodine exposure is shown in table II. The incidence of exposure to radioopaque media and iodine-containing drugs was significantly greater in group B than group A, whereas that of exposure to other drugs or well water did not differ significantly. The time elapsed since exposure to radioopaque media and the type of investigation are shown in table III. All four patients of group B who had had intravenous pyelograms had also had a cholecystogram performed (one in the previous six months and three more than five years earlier). The evidence of iodine contamination in patients who had had cholecystograms more than five years before, while those in the intervening period appear to be unaffected, is interesting but no explanation could be found. In this small number of cases it may be fortuitous. Three had also used iodine-containing drugs.

\begin{tabular}{lllll}
\hline & $\begin{array}{l}\text { I-containing } \\
\text { Drugs }\end{array}$ & $\begin{array}{l}\text { Radioopaque } \\
\text { Media }\end{array}$ & Other Drugs & $\begin{array}{l}\text { Well } \\
\text { Water }\end{array}$ \\
\hline Group A & 12.3 & 16.2 & 36.8 & 16.8 \\
Group B & 31.6 & 39.5 & 44.7 & 23.7 \\
Significance & $\mathrm{P}<0.05$ & $\mathrm{P}<0.05$ & $\mathrm{NS}$ & $\mathrm{NS}$ \\
\hline
\end{tabular}

Table II Exposure of patients to possible sources of iodine contamination ${ }^{1}$

${ }^{1}$ A single patient may appear in more than one group.

\begin{tabular}{|c|c|c|c|c|c|}
\hline \multirow{2}{*}{$\begin{array}{l}\text { Time } \\
\text { Elapsed }\end{array}$} & \multicolumn{2}{|l|}{ Group $A^{1}$} & \multicolumn{3}{|l|}{ Group $B^{1}$} \\
\hline & Cholecystogram & $I V P$ & Cholecystogram & $I V P$ & Other \\
\hline $0-6 \mathrm{mth}$ & 1 & 2 & $5(3)$ & 0 & $1^{2}$ \\
\hline 6-12 mth & 3 & 3 & 0 & 0 & 0 \\
\hline $1-5 \mathrm{yr}$ & 5 & 6 & 0 & $2^{2}$ & $1^{*}(1)$ \\
\hline $5-10$ yr & 5 & 2 & $4(2)$ & $1^{2}$ & \\
\hline$>10 \mathrm{yr}$ & 3 & 1 & $3(1)$ & $1^{2}$ & $1^{D}(1)$ \\
\hline
\end{tabular}

Table III Time elapsed since exposure to radioopaque media and the type of procedure ${ }^{2}$

${ }^{1}$ The number of patients in each group undergoing each procedure is shown

2also had cholecystogram

Angiogram

bIv cholangiogram

() indicates the number of patients with PBI values of greater than $20 \mu \mathrm{g} / \mathrm{dl}$

Of the 16 patients with PBI values of greater than $20 \mu \mathrm{g} / \mathrm{dl}$, eight had had radioopaque media, one had recently taken Enterovioform, and seven had no history of iodine exposure. In all, 17 patients in group B $(45 \%)$ had no history suggesting a source of iodine contamination.

\section{FINDINGS IN HYPOTHYROID PATIENTS}

Of the total 287 patients studied 12 were diagnosed as being hypothyroid on the basis of the laboratory results including, where indicated, the results after TSH stimulation. Three of these $(25 \%)$ had dI values of greater than $2.0 \mu \mathrm{g} / \mathrm{dl}$. In two this resulted in PBI and FTI(PBI) values well within the normal range. Neither responded to TSH. The findings in these two patients are shown in table IV.

\begin{tabular}{|c|c|c|c|}
\hline Test & $\begin{array}{l}\text { Patient } 93 \\
(M .86)\end{array}$ & $\begin{array}{l}\text { Patient } 215 \\
(F .47)\end{array}$ & $\begin{array}{l}\text { Normal } \\
\text { Range }\end{array}$ \\
\hline $\begin{array}{l}\text { 24-hour }{ }^{131} \text { I neck uptake (\%) } \\
\text { Serum } \mathrm{T}_{4}(\mu \mathrm{g} / \mathrm{dl}) \\
\mathrm{T}_{\mathrm{s}} \text {-resin uptake }(\%) \\
\text { FTI(T, } \\
\text { Serum } \mathrm{PBI}(\mu \mathrm{g} / \mathrm{dl}) \\
\text { FTI(PBI) } \\
\text { dI(PBI-T,I) }(\mu \mathrm{g} / \mathrm{dl}) \\
\text { History of iodine exposure }\end{array}$ & $\begin{array}{l}9 \\
4 \cdot 8 \\
26 \\
1 \cdot 25 \\
6 \cdot 1 \\
1 \cdot 59 \\
3 \cdot 0 \\
\mathrm{Nil}\end{array}$ & $\begin{array}{l}4 \\
4 \cdot 1 \\
24 \\
0 \cdot 98 \\
7 \cdot 4 \\
1 \cdot 78 \\
4 \cdot 7 \\
\text { Throat } \\
\text { lozenges }\end{array}$ & $\begin{array}{l}15-46 \\
5 \cdot 6-12 \cdot 6 \\
25-35 \\
1 \cdot 43-3 \cdot 60 \\
3 \cdot 8-8 \cdot 2 \\
1 \cdot 31 \cdot 2 \cdot 17 \\
<2 \cdot 0\end{array}$ \\
\hline
\end{tabular}

Table IV Results of thyroid function tests on two hypothyroid patients with normal $P B I$ values ${ }^{1}$

${ }^{1}$ Neither responded to TSH stimulation. The normal ranges $(95 \%$ limits) were established in this laboratory.

\section{Discussion}

To establish whether our group A patients are similar to those found elsewhere the findings may be compared with those of other authors. The mean dI of this group was $0.29( \pm 0.9) \mu \mathrm{g} / \mathrm{dl}$. Farran, 
Haiste, and Hoffenberg (1971) found a mean dI of $0.35 \mu \mathrm{g} / \mathrm{dl}$ in 217 euthyroid patients and their diagram indicates a scatter of results similar to ours. Keeling and Williams (1972) found a mean 24-hour 131I neck uptake of $31.9 \%$ in 67 euthyroid patients (the corresponding figure in our group $\mathrm{A}$ is $30.2 \%$ ). These findings indicate that our group of euthyroid patients is comparable to those found elsewhere.

The basis of this study lies in the assumption that the elevated dI values in group B are due to iodine contamination. Farran et al drew attention to an increasing $\mathrm{dI}$ when levels of both $\mathrm{T}_{4} \mathrm{I}$ and PBI are elevated, regardless of cause, which they ascribed to a circulating non-thyroxine iodinated compound. The elevated dI values in the present series cannot be accounted for on the same basis as only two patients had $T_{4}$ levels slightly above the normal range. The combination of elevated $\mathrm{dI}$ and low ${ }^{131} \mathrm{I}$ neck uptake in patients who are not taking thyroid supplements can only be satisfactorily explained on the basis of iodine excess. This being so, the results indicate that almost one in five PBI estimations is falsely elevated.

The significance of this finding is emphasized by the small series of hypothyroid patients, two of whom $(16.7 \%)$ had PBI and FTI(PBI) values well within the normal range. It is realized that without serum TSH estimation or TSH stimulation tests in all clinically suspected patients, early hypothyroidism could be missed. This reservation, however, applies to both $\mathrm{T}_{4}$ and PBI estimations.

Similarly, there were 16 euthyroid patients with PBI values ranging from 8.4 to $15.6 \mu \mathrm{g} / \mathrm{dl}$, levels which could cause diagnostic confusion or misdiagnosis. The 16 patients with PBI values greater than $20 \mu \mathrm{g} / \mathrm{dl}$ would almost certainly be recognized $\frac{0}{\sigma}$
as contaminated.

There is no sure way of predicting which patients will have falsely raised PBI values. Certainly alls who have had cholecystograms or angiograms inc the previous six months should be suspected whereas, in this small series, intravenous pyelography seems less troublesome. Other procedures using iodine- $\triangle$ containing radioopaque media such as myelographyo are known to affect thyroid function tests for many years (Acland, 1971). Excluding all patients with:any history of such procedures or of iodine intake $\overrightarrow{\vec{\omega}}$ would limit the problem but in $45 \%$ of those affected in the present series no such history was obtained on direct questioning. In many contamination was massive.

As serum thyroxine estimation by methods notio involving measurement of iodine are widely availablecto there seems no good reason to continue using a test? with such a high incidence of false results. Proteinbound iodine estimation should not be considered as an acceptable alternative to thyroxine estimation either directly or for use in calculating the FTI.

References

Acland, J. D. (1971). The interpretation of the serum protein-bound iodine: a review. J. clin. Path., 24, 187-218.

Bayliss, R., and Hall, R. (1973). Thyroid gland. Medicine S.A., 2 109-124.

Farran, H. E. A., Haiste, C., and Hoffenberg, R. (1971). A comparisori of serum PBI and thyroxine iodine levels. Acta endocr., 68, 451-457. Flynn, F. V., and Hobbs, J. R. (1971). The assessment of thyroif
function. Ann. clin. Biochem., 8, 59-72.

Keeling, D. H., and Williams, E. S. (1972). Changes in the norma range of thyroidal radio-iodine uptake. J. clin. Path., 250 863-866. 